\title{
Differentiating Cyberbullies and Internet Trolls by Personality Characteristics and Self-Esteem
}

Lauren A. Zezulka

The University of Alabama

Kathryn C. Seigfried-Spellar

Purdue University, kspellar@purdue.edu

Follow this and additional works at: https://commons.erau.edu/jdfsl

Part of the Computer Engineering Commons, Computer Law Commons, Electrical and Computer Engineering Commons, Forensic Science and Technology Commons, and the Information Security Commons

\section{Recommended Citation}

Zezulka, Lauren A. and Seigfried-Spellar, Kathryn C. (2016) "Differentiating Cyberbullies and Internet Trolls by Personality Characteristics and Self-Esteem," Journal of Digital Forensics, Security and Law. Vol. 11 : No. 3 , Article 5. DOI: https://doi.org/10.15394/jdfsl.2016.1415

Available at: https://commons.erau.edu/jdfsl/vol11/iss3/5

This Article is brought to you for free and open access by

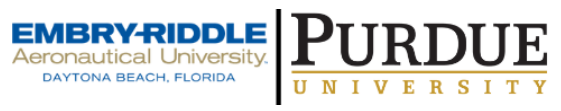
the Journals at Scholarly Commons. It has been accepted for inclusion in Journal of Digital Forensics, Security and Law by an authorized administrator of (c)ADFSL Scholarly Commons. For more information, please contact commons@erau.edu. 


\title{
DIFFERENTIATING CYBERBULLIES AND INTERNET TROLLS BY PERSONALITY CHARACTERISTICS AND SELF-ESTEEM
}

\author{
Lauren A. Zezulka \\ The University of Alabama \\ Kathryn C. Seigfried-Spellar \\ Purdue University \\ kspellar@purdue.edu \\ (Corresponding Author)
}

\begin{abstract}
Cyberbullying and internet trolling are both forms of online aggression or cyberharassment; however, research has yet to assess the prevalence of these behaviors in relationship to one another. In addition, the current study was the first to investigate whether individual differences and self-esteem discerned between self-reported cyberbullies and/or internet trolls (i.e., Never engaged in either, Cyberbully-only, Troll-only, Both Cyberbully and Troll). Of 308 respondents solicited from Mechanical Turk, 70 engaged in cyberbullying behaviors, 20 engaged in only trolling behaviors, 129 self-reported both behaviors, and 89 self-reported neither behavior. Results yielded low self-esteem, low conscientiousness, and low internal moral values for both cyberbullying and trolling behaviors. However, there were differentiating factors between individuals who only engaged in cyberbullying behaviors (high on neuroticism) vs. trolling-only behaviors (high on openness to experience). Individuals who engaged in both behaviors scored higher on extraversion, lower on agreeableness, and lower on self-esteem compared to individuals who engaged in neither behavior.
\end{abstract}

Keywords: Cyberbullying, Internet Trolling, Electronic Harassment, Self-Esteem, Individual Differences, Personality

\section{INTRODUCTION}

With the continuous growth of technology, targeted aggression and harassment have expanded into the cyber realm of society. Cyberbullying is an "aggressive, intentional act carried out by a group or individual, using electronic forms of contact, repeatedly and over time against a victim who cannot easily defend him or herself" (Smith et al., 2008, p.
376). Cyberbullying has received heightened attention after several publicized instances of victims committing suicide (c.f., Hinduja and Patchin, 2010), such as the case of Rebecca Sedwick (Stanglin and Welch, 2013). Victims of cyberbullying experience a range of psychosocial effects, including poor school performance (Patchin \& Hinduja, 2006) and suicidal ideation (Schenk \& Fremouw, 2012). However, research has also found that 
instigators of cyberbullying experience suicidal ideation (Hinduja \& Patchin, 2010; Schenk et al., 2013) and depression (Kokkinos et al., 2014; Schenk et al., 2013).

In comparison, a less understood form of online harassment is internet trolling (c.f., Phillips, 2015). Trolling is an act, which is similar to cyberbullying, in that it is a form of online harassment. According to Buckels et al. (2014), trolling is "the practice of behaving in a deceptive, destructive, or disruptive manner in a social setting on the internet with no apparent instrumental purpose" (p. 97). Unlike cyberbullying, which is an extension of traditional bullying in the cyber realm (Del Rey, Elipe, \& Ortega-Ruiz, 2012), internet trolls traditionally do not know their victims. In fact, many trolls deny any connection between their real-world identity and cyber identity (Thompson, 2013). For example, Thompson (2013) recounted an incident in which a female high school student committed suicide after a photo circulated the internet of her being gang-raped. Following her suicide, internet trolls flooded her Facebook memorial page and posted derogatory jokes about her death (Thompson, 2013). This form of trolling is known as RIP trolling; instigators post derogatory comments and images onto a memorial page or obituary comment section (Phillips, 2011).

Cyberbullying and internet trolling are both forms of cyberharassment, often referred to as cyber aggression or online aggression (c.f., Corcoran, McGuckin, \& Prentice, 2015; Grigg, 2010). In addition, cyberbullying and trolling are both influenced by the anonymous nature of the internet (c.f., Menesini et al., 2012; Santana, 2014), and online disinhibition plays a role in both forms of cyber aggression (c.f., Suler, 2004). Cyberbullying and trolling are a recognized social problem with similar characteristics, however, research has yet to assess the relationship between these two forms of online aggression. The aim of this study is to add to the body of literature on cyberbullying and trolling by assessing the relationship between cyberbullying and trolling as well as exploring whether individual differences and self-esteem discriminate between both forms of online aggression.

\subsection{Individual Differences \& Self- Esteem}

\subsubsection{Cyberbullies}

Previous research regarding cyberbullying primarily focuses on the overlap and similarities between cyberbullying and traditional bullying (Casas et al., 2013; ErdurBaker, 2010; Vandebosch \& Van Cleemput, 2009), but only a moderate amount of research has assessed the role of self-esteem and individual differences. For self-esteem and traditional bullying, the findings are inconsistent; some studies suggest traditional bullies have lower self-esteem (Frisén et al., 2007; Jankauskiene et al., 2008; O'Moore \& Kirkham 2001), whereas others suggest they are more likely to report high self-esteem (Rigby \& Slee, 1991; Salmivalli et al. 1999). Fewer studies, however, have assessed the relationship between self-esteem and cyberbullying, and these findings also remain inconsistent. Patchin and Hinduja (2010) found low self-esteem to be a significant risk factor for engaging in cyberbullying behavior, whereas Corcoran et al. (2012) found high selfesteem to be a significant risk factor. Finally, Brack and Caltabiano (2014) found no significant difference in scores on self-esteem for cyberbullies and non-cyberbullies.

Unlike self-esteem, more empirical research exists on the individual differences of cyberbullies. In general, high neuroticism (i.e., low emotional stability) appears to be a consistent predictor of cyberbullying behavior (Çelik et al., 2012; Ojedokun \& Idemudia, 2013; Seigfried-Spellar \& Treadway, 2014). 
Previous research also suggests psychoticism (Arıcak, 2009; Ozden \& Icellioglu, 2013) and hostility/aggression are significant predictors of cyberbullying (Arıcak, 2009; Schenk et al., 2013). Furthermore, cyberbullies are more likely to score significantly lower on agreeableness, a trait associated with asserting dominance and hostility towards others (i.e., high antagonism; Çelik et al., 2012; Festl \& Quandt, 2013; Seigfried-Spellar \& Treadway, 2014). For instance, Gibb and Devereux (2014) found cyberbullies scored significantly higher on Machiavellianism and psychopathy compared to non-cyberbullies.

Finally, previous research suggests cyberbullies are less likely to make moral decisions based on a personal moral compass (i.e., low internal moral values) compared to non-cyberbullies (Seigfried-Spellar \& Treadway, 2014). In addition, Renati et al. (2012) and Sticca et al. (2013) argue moral disengagement plays a central role for the instigator of cyberbullying. Less consistent are the findings for extraversion and conscientiousness. A few studies suggest cyberbullies are more extraverted compared to non-cyberbullies (Festl \& Quandt, 2013; Ojedokun \& Idemudia, 2013); however, Çelik et al. (2012) found cyberbullies are significantly more introverted compared to non-cyberbullies. In addition, Çelik et al. (2012) found cyberbullies scored significantly lower on conscientiousness compared to noncyberbullies. Overall, empirical research is beginning to assess the individual differences of cyberbullies; however, there remains inconsistent findings or too few studies for a definitive understanding.

\subsubsection{Internet Trolls}

Due to the novelty of internet trolling, few empirical research studies have assessed the individual differences associated with internet trolling, and no empirical research has assessed self-esteem and trolling. In fact, the majority of research on internet trolls involves qualitative interviews (c.f., Bishop, 2013; Schachaf \& Hara, 2010) or the content analysis of posts on a forum (c.f., Hardaker, 2010). For instance, after in-depth interview with a troll, Bishop (2013) suggested features of psychopathy and antisocial-personality disorder were present. However, a recent empirical study by Buckels et al. (2014) assessed the relationship between trolling and different personality traits (i.e., Big Five, Dark Tetrad). The authors found trolling was positively correlated with psychopathy, sadism and Machiavellianism; however, sadism proved to be the most important factor for predicting trolling behaviors (Buckels et al., 2014). Although this finding was not discussed further in the article, Buckets et al. (2014) reported internet trolls scored higher on extraversion and lower on agreeableness compared to nontrolls.

\subsection{Current Study}

Overall, research suggests that personality characteristics are associated with cyberbullying behavior; however, these findings have been inconsistent (e.g., self-esteem, extraversion). In addition, few empirical studies have examined the relationship between trolling and individual differences. Thus, the current study will add to the body of knowledge by providing further evidence as to the individual differences associated with trolling and cyberbullying behaviors. This study will also be the first to explore the similarities and/or differences in personality characteristics and self-esteem for individuals who self-report engaging in cyberbullies and trolls. Secondly, this study will be the first to assess the relationship between cyberbullying and trolling behaviors, which are both forms of electronic harassment. There are no studies to the authors' knowledge that assess the prevalence of individuals who engage in both 
forms of online aggression (e.g., individuals who engage in both cyberbullying and trolling behaviors), and whether individuals are more likely to engage in both forms of online aggression rather than just one. Cyberbullying and trolling behaviors are both forms of electronic or online harassment, thus is it important to address the likelihood of someone engaging in both forms of electronic harassment. Finally, the current literature tends to treat cyberbullying as either a dichotomous (No/Yes) or continuous variable based on frequency (i.e., how often someone bullies). However, there are a variety of behaviors associated with electronic harassment (e.g., slut-shaming, flaming, outing). In the current study, we were not interested in "how often" a behavior occurred but in "how many" types an individual selfreported.

To address these gaps, the current study explored four hypotheses. First, the authors expected to find individual differences predictive of cyberbullying, specifically low agreeableness, high neuroticism, and low internal moral values will be predictive of individuals who engage in more cyberbullying behaviors. Second, the authors expected to find individual differences predictive of trolling, specifically low agreeableness and high extraversion will be predictive of individuals who engage in more trolling behaviors. Due to the lack of previous research assessing individual differences between cyberbullies and trolls, no specific direction or variations in traits were predicted for the next two hypotheses although differences were expected. Therefore, the authors expected to find personality differences between individuals who never engaged in cyberbullying or trolling (i.e., Never) vs. individuals who only engaged in cyberbullying (CB-only), individuals who only engaged in trolling (Troll-only), and individuals who engaged in both cyberbullying and trolling (Both). Finally, the authors expected to find individual differences between individuals who self-reported engaging in trolling-only vs. cyberbullying-only behaviors.

\section{METHODS}

\subsection{Participants}

A sample of participants from the general population of internet users was recruited from the Amazon ${ }^{\circledR}$ website, Mechanical Turk ${ }^{\circledR}$. Initially, 331 respondents began the study, and the final dataset for statistical analyses included 308 respondents after dropping respondents due to missing data or invalid responses. As shown in Table 1, 106 (34.4\%) were men and $201(65.3 \%)$ were women. The majority $(n=199,64.6 \%)$ of the respondents were White $(n=229,74.4 \%)$, and their ages ranged from 19 to 73 years $(M=35, S D=$ 12.53). All respondents were treated in accordance with the ethical standards set forth by the American Psychological Association (APA).

\subsection{Measures}

The current study comprised of a number of questionnaires previously used or adapted from studies assessing cyberdeviancy (Rogers, 2001; Rogers et al., 2006a; Rogers et al., 2006b; Seigfried-Spellar \& Treadway, 2014). The current study included the following questionnaires: demographics, Cyberbully/Troll Deviancy Scale (CTDS), Five-Factor Model Rating Form (FFMRF; see Widiger, 2004), Moral Decision-Making Scale (MDKS; Rogers et al., 2006b), and Rosenberg's Self Esteem Scale (RSES; Rosenberg, 1965). The demographics survey appeared at the beginning of the study for all the respondents to increase the accuracy of self-reported subject variables (e.g., sex; see Birnbaum, 2000).

To measure the respondents' cyberbullying and trolling behaviors, the authors created the Cyberbully/Troll Deviancy Scale (CTDS; See 
Appendix). The authors were unable to locate a previously validated scale that assessed a variety of trolling behaviors; in addition, the authors did not want to include the words "cyberbullying" or "trolling" in the measure as to not influence the respondents. Thus, the authors were careful to describe the behaviors they were interested in measuring rather than label them (e.g., slut-shaming, flaming). Prior to implementing the study, the Cyberbully/Troll Deviancy Scale (CTDS) was reviewed by several colleagues who assessed the structure and face validity of the survey items.

For the cyberbully section, the authors modified and/or included 14 of 19 questions from the "Are You A Cyberbully?" survey at http://www.stopcyberbullying.org

(see "Stopcyberbulling.org", n.d.; see Diamanduros et al., 2008). The "Are You A Cyberbully" survey measures the prevalence of different types of cyberbullying behaviors and is used to develop student self-awareness for different examples of cyberbullying behaviors (Diamanduros et al., 2008). In the current study, the authors modified the "Are You A Cyberbully" survey by removing five of the questions that measured unauthorized access behaviors (i.e., hacking) rather than electronic harassment in order to focus solely on cyberbullying behaviors. Finally, the trolling section of the CTDS included 13 questions created by the authors; these items were created since there was no previous survey available that measured the different types of trolling behaviors (see Appendix). Overall, the CTDS comprised of 27 items assessing different types of cyberbullying and trolling behaviors.

For the CTDS, the following statement preceded the 27 items: "How often in the past five years have you engaged in the following behaviors..." Since some cyberbullying and trolling behaviors are similar (e.g., use of derogatory language), the authors distinguished between the behaviors by focusing on whether the victim was known to the instigator. Cyberbullying is often related to a specific offline social context and is a continuation of traditional bullying (Del Rey et al., 2014), whereas trolls exist as a subculture of the internet who target individuals or groups in order to obtain "lolz" (Phillips, 2015), so cyberbullies usually target someone that they know, whereas trolls do not. Thus, the cyberbullying section included the phrase "someone that you know" whereas the trolling section included the phrase "someone that you do not know" or "stranger" to differentiate between cyberbullying and trolling behaviors. All CTDS items were scaled from 1 (Never) to 5 (6 or more times); a sample statement measuring cyberbullying was: "Posted a video of someone that you know in order to portray them as a slut without their consent?" A sample statement assessing trolling behaviors was: "Used profanity or insulting language towards a stranger online (just because)?" For the CTDS, the Cronbach's alpha for the cyberbully section was $\alpha=.89$ and $\alpha=.93$ for the trolling section.

The Five-Factor Model Rating Form (FFMRF; Widiger, 2004) measured the respondents' individual differences based on the Big 5 personality characteristics: Neuroticism, Extraversion, Openness to Experience, Agreeableness, and Conscientiousness. The FFMRF displays 30 polar opposites on a Likert scale of 1 (Extremely Low) to 5 (Extremely High). In the current study, the FFMRF yielded acceptable Cronbach's alphas for all five factors: Neuroticism $(\alpha=.78)$, Extraversion $(\alpha$ $=.77)$, Openness to Experience $(\alpha=.72)$, Agreeableness $(\alpha=.80), \quad$ and Conscientiousness $(\alpha=.83)$. 


\section{$2.3 \quad$ Procedures}

The internet-based study was hosted on Qualtrics ${ }^{\circledR}$, and the respondents were solicited from Mechanical Turk ${ }^{\circledR}$. Mechanical Turk ${ }^{(}$ may be used to obtain high-quality data inexpensively and provides better generalizability than snowball sampling procedures (c.f., Berinsky et al., 2011; Buhrmester et al., 2011). Respondents were compensated .10థ using Amazon's anonymous and secure compensation procedures. The study was advertised on Mechanical Turk as "Anonymous Survey: Attitudes Toward Online Communications." The survey was completely anonymous in that no identifying information was collected (e.g., name, IP address). To qualify, the respondents had to be at least 19 years of age or older and permanent residents of the United States. Once completed, the respondents were provided with a "code word" which they anonymously submitted to the authors through Mechanical Turk's website in order to be compensated. The code word was changed daily, and the Qualtrics software allowed the authors to prevent ballot box stuffing.

\subsection{Analytical Strategies}

Two-tailed statistical significance was set at the alpha level of .05 prior to any analyses; however, findings at the alpha level of .10 were included due to the exploratory nature of this study (Tabachnick \& Fidell, 2007; Warner, 2007). Two continuous variables (i.e., CB Types and Troll Types), one multinomial variable (CB-Troll Categories), and one binary variable (CB-only vs. Troll-only) were created for this study. Based on responses to the cyberbullying section of the CTDS, respondents scored from 0 (None) to 14 (All Types) depending on the number of different cyberbullying behaviors endorsed (CB Types). In addition, respondents scored from 0 (None) to 13 (All Types) depending on the number of different trolling behaviors endorsed on the trolling section of the CTDS (Troll Types). For the two continuous variables (CB Types, Troll Types), the authors first conducted a zero order correlation to identify any personality and cognitive variables significantly associated with cyberbullying or trolling behaviors. Next, only the variables significantly correlated with CB Types or Troll Types were entered into a backward multiple linear regression to determine the best predictive model for cyberbullying and trolling.

The multinomial variable (CB-Troll Category) differentiated between individuals who never engaged in either cyberbullying or trolling behaviors (Never $=0$ ), individuals who only engaged in cyberbullying behaviors (CBonly $=1$ ), individuals who only engaged in trolling behaviors (Troll-only $=2$ ), and individuals who self-reported engaging in both cyberbullying and trolling behaviors (Both = 3 ). For the multinomial variable (CB-Troll Category), a multinomial (Wald) logistic regression was conducted to determine which personality and cognitive characteristics distinguished between the different cyberbullying and trolling behaviors. See Table 2 for mean differences across groups.

Finally, a binary variable (CB-only vs. Troll-only) was created which represented two different groups: those respondents who only engaged in cyberbullying behaviors (CB-only = $0)$, and respondents who only engaged in trolling behaviors (Troll-only $=1$ ). First, a zero-order correlation was conducted to determine which individual differences were significantly associated with cyberbully-only vs. troll-only behaviors. Next, the statistically significant traits from the zero-order correlation were entered into a backward stepwise (Wald) logistic regression (LR) to determine the best model for differentiating between cyberbullying-only vs. trolling-only individuals. 
Table 2

Mean Differences Across Groups (Neither, Cyberbully-only, Troll-only, Both)

\begin{tabular}{|c|c|c|c|c|c|c|c|c|c|}
\hline & \multicolumn{5}{|c|}{ FFMRF } & \multicolumn{3}{|c|}{ MDKS } & \multirow{2}{*}{$\frac{\text { Self-Esteem }}{\mathrm{SE}}$} \\
\hline & $\mathrm{E}$ & $\mathrm{N}$ & $\mathrm{O}$ & $\mathrm{A}$ & $\mathrm{C}$ & SV & IV & $\mathrm{HV}$ & \\
\hline \multicolumn{10}{|c|}{ CB-Troll Category } \\
\hline Neither & $2.95(.77)$ & $2.33(.85)$ & $3.18(.76)$ & $3.57(.83)$ & $3.81(.70)$ & $4.67(1.17)$ & $5.87(1.06)$ & $5.32(1.10)$ & $3.96(.87)$ \\
\hline CB-Only & $2.88(.65)$ & $2.68(.62)$ & $3.27(.68)$ & $3.35(.83)$ & $3.65(.75)$ & $4.69(1.00)$ & $5.78(0.82)$ & $5.30(0.92)$ & $3.55(.83)$ \\
\hline Troll-Only & $3.15(.63)$ & $2.43(.66)$ & $3.61(.82)$ & $3.45(.72)$ & $3.48(.74)$ & $4.64(1.33)$ & $6.07(0.97)$ & $5.33(1.27)$ & $3.58(.83)$ \\
\hline Both & $3.02(.73)$ & $2.65(.68)$ & $3.36(.69)$ & $3.20(.72)$ & $3.46(.74)$ & $4.36(1.09)$ & $5.48(0.96)$ & $5.04(1.02)$ & $3.39(.90)$ \\
\hline \multicolumn{10}{|c|}{$\begin{array}{l}\text { Note. Values represent means with standard deviations in parentheses. } \mathrm{CB}=\text { Cyberbully; Both }=\text { Cyberbully and Troll. FFMRF (Five-Factor } \\
\text { Model Rating Form): } \mathrm{N}=\text { Neuroticism, } \mathrm{E}=\text { Extraversion, } \mathrm{O}=\text { Openness to Experience, } \mathrm{A}=\text { Agreeableness, } \mathrm{C}=\mathrm{Conscientiousness.} \mathrm{Scale} \\
\text { ranges from } 1 \text { (Extremely Low) to } 5 \text { (Extremely High); MDKS = Moral Decision-Making Scale: } \mathrm{IV}=\text { Internal Values, } \mathrm{SV}=\mathrm{Social} \text { Values, } \mathrm{HV}= \\
\text { Hedonistic Values. MDKS scale ranges from } 1 \text { (Not Important) to } 7 \text { (Very Important). Self-Esteem scale ranges from } 1 \text { (Strongly Agree) to } 5 \\
\text { (Strongly Disagree). }\end{array}$} \\
\hline
\end{tabular}

\section{RESULTS}

\subsection{Descriptives}

Of the 308 respondents, 89 (29\%) self-reported never engaging in either cyberbullying or trolling behaviors, 70 (23\%) respondents selfreported engaging in only cyberbullying behaviors, and 20 (6\%) respondents only engaged in trolling behaviors. In addition, 129 of the $308(42 \%)$ respondents self-reported both cyberbullying and trolling behaviors (see Table 1). For trolling, 159 (52\%) of the respondents self-reported never engaging in trolling behaviors (i.e., never). On average, respondents self-reported engaging in 2.63 (SD $=3.47)$ different types of cyberbullying behaviors and $2.31(S D=3.65)$ different types of trolling behaviors. No one self-reported engaging in all 14 cyberbullying behaviors although 18 individuals self-reported engaging in 13 of them. Finally, 16 individuals selfreported engaging in all 13 trolling behaviors.

\subsection{Hypothesis Testing}

\subsubsection{H1}

Low agreeableness, high neuroticism, and low internal moral values will be predictive of individuals who engage in more cyberbullying behaviors.

First, the zero-order correlation suggested that individuals who engaged in more cyberbullying behaviors were more neurotic, less agreeable, less conscientious, and selfreported lower self-esteem. In addition, individuals who engaged in more cyberbullying types were less likely to make moral decisions based on social, moral, or hedonistic values (see Table 3). Next, only the statistically significant variables identified in the zero-order correlation were entered into a backward stepwise multiple linear regression to identify the best predictive model for cyberbullying. As shown in Table 4, results suggested the following variables were the best predictors of individuals engaging in more cyberbullying types: low self-esteem $(\mathrm{t}=-2.62, \mathrm{p}<.01)$, low conscientiousness $(\mathrm{t}=-3.57, \mathrm{p}<.01)$, and low internal moral values $(\mathrm{t}=-5.92, \mathrm{p}<.01)$. In addition, variance inflation factors (VIF) and condition index values were calculated in order to test for multicollinearity, all of which indicated no cause for concern (Self-Esteem: $\mathrm{VIF}=1.01 ;$ Conscientiousness: VIF $=1.09$; Internal Moral Values: VIF $=1.06$; Condition Index $<30)$. 
Table 3

Zero-order correlation between individual differences and cyberbullying types vs. trolling types.

\begin{tabular}{|c|c|c|c|c|c|c|c|c|c|c|c|}
\hline & $\mathrm{CB}$ & Troll & $\mathrm{SE}$ & $\mathrm{N}$ & E & $\mathrm{O}$ & A & $\mathrm{C}$ & SV & IV & $\mathrm{HV}$ \\
\hline $\mathrm{CB}$ & 1 & $0.82 * * *$ & $-0.25 * * *$ & $0.22 * * *$ & 0.09 & 0.03 & $-0.12 * *$ & $-0.29 * * *$ & $-0.14 * *$ & $-0.38 * * *$ & $-0.14 * *$ \\
\hline Troll & & 1 & $-0.23 * * *$ & $0.16 * * *$ & 0.07 & 0.06 & $-0.14 * *$ & $-0.27 * * *$ & $-0.19 * * *$ & $-0.31 * * *$ & $-0.18 * * *$ \\
\hline SE & & & 1 & $-0.60 * * *$ & $0.34 * * *$ & -0.06 & 0.02 & $0.25 * * *$ & $0.17 * * *$ & $0.19^{* * *}$ & 0.03 \\
\hline $\mathrm{N}$ & & & & 1 & $-0.37 * * *$ & -0.03 & -0.06 & $-0.31 * * *$ & -0.04 & -0.08 & 0.04 \\
\hline $\mathrm{E}$ & & & & & 1 & $0.22 * * *$ & 0.05 & -0.09 & $0.10^{*}$ & 0.06 & -0.03 \\
\hline $\mathrm{O}$ & & & & & & 1 & $0.17 * * *$ & $0.27 * * *$ & $-0.19 * * *$ & $0.18 * * *$ & 0.02 \\
\hline A & & & & & & & 1 & 0.05 & $0.21 * * *$ & $0.21 * * *$ & 0.03 \\
\hline $\mathrm{C}$ & & & & & & & & 1 & $0.13 * *$ & $0.18 * * *$ & 0.09 \\
\hline SV & & & & & & & & & 1 & $0.46^{* * *}$ & $0.44 * * *$ \\
\hline IV & & & & & & & & & & 1 & $0.50 * * *$ \\
\hline $\mathrm{HV}$ & & & & & & & & & & & 1 \\
\hline
\end{tabular}

$* * * p<.00 \quad * * p<.05 \quad * p<.10$

Listwise $N=297$

Note. $\mathrm{CB}=$ Cyberbullying Types; Troll = Trolling Types; $\mathrm{SE}=$ Self-Esteem; $\mathrm{N}=$ Neuroticism; $\mathrm{E}=$ Extraversion; $\mathrm{O}=\mathrm{Openness}$ to Experience; $\mathrm{A}=$ Agreeableness; $\mathrm{C}=$ Conscientiousness; $\mathrm{SV}=$ Social Moral Values; IV = Internal Moral Values; $\mathrm{HV}=$

Hedonistic Moral Values 
Table 4

Backward stepwise multiple linear regression of individuals' differences on cyberbullying types

\begin{tabular}{|c|c|c|c|}
\hline Variable & $B$ & $S E B$ & $\beta$ \\
\hline \multicolumn{4}{|l|}{ Step 1} \\
\hline $\mathrm{SE}$ & -0.39 & 0.24 & $-.11 *$ \\
\hline $\mathrm{N}$ & 0.31 & 0.30 & 0.01 \\
\hline A & -0.18 & 0.22 & -0.05 \\
\hline $\mathrm{C}$ & -0.80 & 0.24 & $-.18 * * *$ \\
\hline SV & 0.20 & 0.18 & 0.07 \\
\hline IV & -1.19 & 0.22 & $-.35 * * *$ \\
\hline $\mathrm{HV}$ & 0.07 & 0.20 & 0.02 \\
\hline \multicolumn{4}{|l|}{ Step 2} \\
\hline SE & -0.39 & 0.24 & $-.11 *$ \\
\hline $\mathrm{N}$ & 0.32 & 0.30 & 0.07 \\
\hline A & -0.19 & 0.22 & -0.05 \\
\hline $\mathrm{C}$ & -0.80 & 0.24 & $-.18 * * *$ \\
\hline SV & 0.22 & 0.17 & 0.07 \\
\hline IV & -1.16 & 0.20 & $-0.34 * * *$ \\
\hline \multicolumn{4}{|l|}{ Step 3} \\
\hline $\mathrm{SE}$ & -0.38 & 0.24 & -0.11 \\
\hline $\mathrm{N}$ & 0.34 & 0.29 & 0.08 \\
\hline $\mathrm{C}$ & -0.79 & 0.24 & $-.18 * * *$ \\
\hline SV & 0.19 & 0.17 & 0.07 \\
\hline IV & -1.18 & 0.20 & $-.35 * * *$ \\
\hline \multicolumn{4}{|l|}{ Step 4} \\
\hline $\mathrm{SE}$ & -0.35 & 0.24 & -0.10 \\
\hline $\mathrm{N}$ & 0.36 & 0.29 & 0.08 \\
\hline $\mathrm{C}$ & -0.78 & 0.24 & $-.18 * * *$ \\
\hline IV & -1.08 & 0.18 & $-.32 * * *$ \\
\hline \multicolumn{4}{|l|}{ Step 5} \\
\hline SE & -0.51 & 0.19 & $-.14 * *$ \\
\hline $\mathrm{C}$ & -0.84 & 0.24 & $-.19 * * *$ \\
\hline IV & -1.07 & 0.18 & $-.32 * * *$ \\
\hline \multicolumn{4}{|c|}{$\begin{array}{l}R^{2}=0.22 \text { for Step } 1 ; \Delta R^{2}=0.00 \text { for Step } \\
2 ; \Delta R^{2}=-0.002 \text { for Step } 3 ; \Delta R^{2}=-0.003 \\
\text { for Step } 4 ; \Delta R^{2}=-0.004 \text { for Step } 5 .\end{array}$} \\
\hline \multicolumn{4}{|c|}{$\begin{array}{l}\text { Note. } \mathrm{SE}=\text { Self-Esteem; } \mathrm{N}=\text { Neuroticism; } \\
\text { Agree = Agreeableness; } \mathrm{SV}=\text { Social } \\
\text { Values; } \mathrm{C}=\text { Conscientiousness; } \mathrm{IV}= \\
\text { Internal Values; } \mathrm{HV}=\text { Hedonistic Values }\end{array}$} \\
\hline
\end{tabular}

\section{$3.2 .2 \quad \mathbf{H}_{2}$}

Low agreeableness and high extraversion will be predictive of individuals who engage in more trolling behaviors.

The zero-order correlation suggested the following variables are significantly associated with individuals who engage in more trolling types: low self-esteem, high neuroticism, low agreeableness, low conscientiousness, and low social, internal, and hedonistic values (see Table 3). The significant traits identified in the zero-order correlation were entered into a backward stepwise multiple linear regression to identify the best predictive model for trolling types. As shown in Table 5, results suggested the following variables were the best predictors of individuals engaging in more trolling types: low self-esteem $(\mathrm{t}=-2.39, \mathrm{p}=.02)$, low conscientiousness $(\mathrm{t}=-3.34, \mathrm{p}<.01)$, and low internal moral values $(\mathrm{t}=-4.52, \mathrm{p}<.01)$. In addition, variance inflation factors (VIF) and condition index values were calculated in order to test for multicollinearity, all of which indicated no cause for concern (Self-Esteem: $\mathrm{VIF}=1.09$; Conscientiousness: VIF $=1.09$; Internal Moral Values: VIF $=1.06$; Condition Index <30).

\section{$3.2 .3 \quad \mathbf{H}_{3}$}

There are individual differences between individuals who never engaged in cyberbullying or trolling (i.e., Neither) vs. cyberbullying-only (CB-only), troll-only (Troll-only), and both cyberbullying and trolling (Both) categories.

As shown in Table 6, individuals with high scores on neuroticism, $X^{2}(1)=3.15, p=.07$, and low scores on agreeableness, $X^{2}(1)=3.71$, $p=.05$, were more likely to engage in cyberbully-only behaviors (CB-only) compared to those who self-reported never engaging in either cyberbullying or trolling behaviors (Neither). Next, individuals with low selfesteem were more likely to engage in troll-only behaviors compared to the "neither" category, 
$X^{2}(1)=3.55, p=.06$. Finally, individuals with low scores on self-esteem, $X^{2}(1)=9.60, p$ $<.01$, and agreeableness, $X^{2}(1)=10.22, p<$ .01 , as well as high scores on extraversion, $X^{2}(1)=5.60, p=.02$, were more likely to selfreport engaging in both cyberbullying and trolling behaviors compared to the "Neither" group. The Pearson and deviance statistics tests were non-significant, implying no issues with overdispersion.

\section{$3.2 .4 \mathbf{H}_{4}$}

There are personality differences between individuals who engage in only cyberbullying vs. only trolling behaviors (i.e., CB-only vs. Troll-only).

First, a zero-order correlation suggested individuals who engaged in trolling-only behaviors were less neurotic, $r_{\mathrm{pb}}(89)=-.17, p$ $<.10$, more extraverted, $r_{\mathrm{pb}}(89)=-.18, p<$ .10 , and more open to experience, $r_{\mathrm{pb}}(89)=-$ $.19, p<.10$, compared to individuals who only engaged in cyberbullying behaviors. Next, the statistically significant personality characteristics from the zero-order correlation were entered into a backward stepwise (Wald) logistic regression (LR).
Table 5

Backward stepwise multiple linear regression of individuals' differences on trolling types

\begin{tabular}{|c|c|c|c|}
\hline Variable & $B$ & $S E B$ & $\beta$ \\
\hline \multicolumn{4}{|l|}{ Step 1} \\
\hline SE & -0.55 & 0.26 & $-.14 * *$ \\
\hline $\mathrm{N}$ & -0.03 & 0.33 & -0.01 \\
\hline A & -0.35 & 0.25 & -0.08 \\
\hline $\mathrm{C}$ & -0.87 & 0.27 & $-.19 * * *$ \\
\hline SV & -0.02 & 0.2 & -0.01 \\
\hline IV & -0.73 & 0.25 & $-.20 * * *$ \\
\hline $\mathrm{HV}$ & -0.18 & 0.22 & -0.06 \\
\hline \multicolumn{4}{|l|}{ Step 2} \\
\hline SE & -0.54 & 0.22 & $-.14 * *$ \\
\hline A & -0.35 & 0.25 & -0.08 \\
\hline $\mathrm{C}$ & -0.86 & 0.26 & $-.19 * * *$ \\
\hline SV & -0.02 & 0.19 & -0.01 \\
\hline IV & -0.73 & 0.24 & $-.20 * * *$ \\
\hline HV & -0.19 & 0.21 & -0.06 \\
\hline \multicolumn{4}{|l|}{ Step 3} \\
\hline $\mathrm{SE}$ & -0.54 & 0.22 & $-.14 * *$ \\
\hline A & -0.35 & 0.24 & -0.08 \\
\hline $\mathrm{C}$ & -0.87 & 0.26 & $-.19 * * *$ \\
\hline IV & -0.74 & 0.24 & $-.20 * * *$ \\
\hline HV & -0.19 & 0.21 & -0.06 \\
\hline \multicolumn{4}{|l|}{ Step 4} \\
\hline SE & -0.52 & 0.22 & $-.14 * *$ \\
\hline $\mathrm{A}$ & -0.33 & 0.24 & -0.08 \\
\hline $\mathrm{C}$ & -0.87 & 0.26 & $-.19 * * *$ \\
\hline IV & -0.85 & 0.21 & $-.23 * * *$ \\
\hline \multicolumn{4}{|l|}{ Step 5} \\
\hline SE & -0.52 & 0.22 & $-.14 * *$ \\
\hline $\mathrm{C}$ & -0.87 & 0.26 & $-.19 * * *$ \\
\hline IV & -0.91 & 0.21 & $-.25 * * *$ \\
\hline \multicolumn{4}{|c|}{$\begin{array}{l}R^{2}=0.17 \text { for Step } 1 ; \Delta R^{2}=0.00 \text { for Step } \\
2 ; \Delta R^{2}=0.00 \text { for Step } 3 ; \Delta R^{2}=-0.002 \text { for } \\
\text { Step } 4 ; \Delta R^{2}=-0.006 \text { for Step } 5 .\end{array}$} \\
\hline \multicolumn{4}{|c|}{$\begin{array}{l}\text { Note. } \mathrm{SE}=\text { Self-Esteem; } \mathrm{N}=\text { Neuroticism; } \\
\text { Agree = Agreeableness; } \mathrm{SV}=\text { Social } \\
\text { Values; } \mathrm{C}=\text { Conscientiousness; } \mathrm{IV}= \\
\text { Internal Values; } \mathrm{HV}=\text { Hedonistic Values }\end{array}$} \\
\hline
\end{tabular}


Table 6

Multinomial (Wald) logistic regression differentiating the different CB-Troll Categories (Never, CB-Only, TrollOnly, Both) by individual differences

\begin{tabular}{|c|c|c|c|}
\hline Variable & $B$ & $S E B$ & $\operatorname{Exp}(B)$ \\
\hline \multicolumn{4}{|c|}{ CB-Only vs. Neither } \\
\hline $\mathrm{N}$ & $0.56^{*}$ & 0.31 & 1.75 \\
\hline $\mathrm{E}$ & 0.22 & 0.28 & 1.25 \\
\hline A & $-0.45^{*}$ & 0.24 & 0.64 \\
\hline $\mathrm{C}$ & 0.03 & 0.27 & 1.03 \\
\hline $\mathrm{O}$ & 0.30 & 0.28 & 1.34 \\
\hline IV & -0.09 & 0.25 & 0.92 \\
\hline SV & 0.23 & 0.20 & 1.26 \\
\hline $\mathrm{HV}$ & -0.08 & 0.20 & 0.93 \\
\hline $\mathrm{SE}$ & -0.40 & 0.26 & 0.67 \\
\hline \multicolumn{4}{|c|}{ Troll-Only vs. Neither } \\
\hline $\mathrm{N}$ & -0.16 & 0.49 & 0.85 \\
\hline $\mathrm{E}$ & 0.59 & 0.43 & 1.81 \\
\hline A & -0.42 & 0.37 & 0.66 \\
\hline $\mathrm{C}$ & -0.39 & 0.41 & 0.68 \\
\hline $\mathrm{O}$ & 0.58 & 0.42 & 1.79 \\
\hline IV & 0.43 & 0.39 & 1.53 \\
\hline SV & 0.13 & 0.29 & 1.14 \\
\hline $\mathrm{HV}$ & -0.16 & 0.31 & 0.85 \\
\hline $\mathrm{SE}$ & $-0.74 *$ & 0.39 & 0.48 \\
\hline \multicolumn{4}{|c|}{ Both vs. Neither } \\
\hline $\mathrm{N}$ & 0.37 & 0.29 & 1.45 \\
\hline $\mathrm{E}$ & $0.61 * *$ & 0.26 & 1.84 \\
\hline A & $-0.70 * * *$ & 0.22 & 0.50 \\
\hline $\mathrm{C}$ & -0.20 & 0.25 & 0.82 \\
\hline $\mathrm{O}$ & 0.34 & 0.26 & 1.40 \\
\hline IV & -0.16 & 0.22 & 0.85 \\
\hline SV & 0.05 & 0.18 & 1.05 \\
\hline $\mathrm{HV}$ & -0.15 & 0.19 & 0.86 \\
\hline $\mathrm{SE}$ & $-0.74 * * *$ & 0.24 & 0.48 \\
\hline \multicolumn{4}{|c|}{$\begin{array}{l}* * * p<.01 \quad * * p<.05 \quad * p<.10 \\
\text { Note. } R^{2}=.20 \text { (Cox \& Snell) } .21 \\
\text { (Nagelkerke). } \mathrm{CB}=\text { Cyberbully; Both }= \\
\text { Cyberbully and Troll; } \mathrm{N}=\text { Neuroticism, } \mathrm{E} \\
=\text { Extraversion, } \mathrm{O}=\text { Openness to } \\
\text { Experience, } \mathrm{A}=\text { Agreeableness, } \mathrm{C}= \\
\text { Conscientiousness, IV = Internal Values, } \\
\mathrm{SV}=\text { Social Values, HV = Hedonistic } \\
\text { Values, } \mathrm{SE}=\text { Self Esteem }\end{array}$} \\
\hline
\end{tabular}

Table 7

Backward stepwise (Wald) logistic regression differentiating cyberbully-only vs. trolling-only behaviors by individual differences.

\begin{tabular}{|c|c|c|c|}
\hline$\underline{\text { Variable }}$ & $B$ & $S E B$ & $\operatorname{Exp}(B)$ \\
\hline \multicolumn{4}{|l|}{ Step 1} \\
\hline $\mathrm{N}$ & -0.72 & 0.47 & 0.49 \\
\hline E & 0.34 & 0.45 & 1.41 \\
\hline $\mathrm{O}$ & $0.68 *$ & 0.40 & 2.00 \\
\hline \multicolumn{4}{|l|}{ Step 2} \\
\hline $\mathrm{N}$ & $-0.79 *$ & 0.46 & 0.46 \\
\hline $\mathrm{O}$ & $0.76 * *$ & 0.39 & 2.14 \\
\hline \multicolumn{4}{|c|}{$\begin{array}{l}* * * p<.01 * * p<.05 * p<.10 \\
\text { Note. } R^{2}=.07 \text { (Hosmer \& Lemeshow) } \\
.072 \text { (Cox \& Snell) } .11 \text { (Nagelkerke). } \\
\mathrm{N}=\text { Neuroticism, } \mathrm{E}=\text { Extraversion, } \mathrm{O}= \\
\text { Openness to Experience }\end{array}$} \\
\hline
\end{tabular}

The final model included neuroticism (Wald $=2.94, p<.10$ ) and openness to experience $($ Wald $=3.83, p<.05$ ) in that individuals who scored high on neuroticism were more likely to be cyberbullies, and individuals who scored high on openness to experience were significantly more likely to be trolls (see Table 7). The Hosmer and Lemeshow test was non-significant, $X^{2}(8)=$ $3.64, p=.89$.

\section{DISCUSSION}

Overall, $65 \%$ of the sample self-reported cyberbullying behaviors and $48 \%$ self-reported trolling behaviors. The prevalence of cyberbullying in the current study is higher than other studies (c.f., MacDonald \& RobertsPittman, 2010; Patchin \& Hinduja, 2006; Seigfried-Spellar \& Treadway, 2014), which may be due to differences in the definition of cyberbullying as well as the sample methodology (c.f., Bryce \& Fraser, 2013; Corcoran et al., 2015; Tokunaga, 2010). For instance, the study measured a variety of 
cyberbullying behaviors (e.g., flaming, slutshaming) without ever using the term "cyberbullying", and it sampled from the general population of internet users instead of school-age adolescents or college students.

Although low agreeableness, high neuroticism, and low internal moral values were significantly correlated with individuals who engaged in more cyberbullying behaviors, the final predictive model only partially supported the authors' hypothesis. As expected, low internal moral values did predict more types of cyberbullying behavior, however, the final predictive model also included low self-esteem and low consciousness. For trolling, the authors' hypothesis was not supported in that extraversion and agreeableness were not predictive of someone who engages in more trolling behaviors (although agreeableness was negatively correlated with trolling); instead, the final model included low self-esteem, conscientiousness and internal moral values. Finally, the authors' hypotheses that individual differences would exist between the cyberbullying-troll categories (Neither, CBonly, Troll-only, and Both) as well as cyberbullying-only vs. trolling-only groups were supported.

While the final predictive model did not include low agreeableness (antagonism) or high neuroticism, both traits were significantly correlated with cyberbullying behaviors, which is consistent with previous research (c.f., Çelik et al., 2012; Ojedokun \& Idemudia, 2013; Seigfried-Spellar \& Treadway, 2014). Neuroticism is characterized by high anxiety, emotional instability, and depression (see Egan, 2009), and past research indicates that cyberbullies are more likely to suffer from depression and emotional instability (GámezGuadix et al., 2013; Schenk et al., 2013). In addition, the current study supported findings that cyberbullies score low on conscientiousness (Çelik et al., 2012). Conscientiousness refers to "constraint" and measures whether the individual is negligent, disorganized, aimless, hedonistic, or hasty (c.f., Krueger \& Tackett, 2006). In addition, previous research suggests that individuals who score low on conscientiousness are more impulsive (Whiteside \& Lynam, 2001), aggressive, and antisocial (Costa \& McCrae, 1992; Miller et al., 2008).

Consistent with Seigfried-Spellar and Treadway (2014), low internal moral values were a significant predictor of cyberbullying behaviors. Essentially, individuals who engage in a variety of cyberbullying behaviors are not guided by their personal moral belief system; in other words, they do not make decisions based on a moral compass (c.f., Rogers et al., 2006a). Finally, as previously discussed, there are inconsistencies in the literature regarding the relationship between self-esteem and cyberbullying; however, the current study supported the findings of Patchin and Hinduja (2010) in that low self-esteem was a significant predictor of cyberbullying behaviors. Overall, the current study suggests that individuals who engage in a variety of cyberbullying behaviors score lower on self-esteem, conscientiousness, and internal moral values.

The current study was the first to assess whether individual differences and self-esteem were significant predictors of individuals who engage in a variety of trolling behaviors. The final predictive model for trolling behaviors yielded similar results as the model for cyberbullying behaviors: low self-esteem, low conscientiousness, and low internal moral values. The similar models may be due to the fact that nearly half $(42 \%)$ of the respondents self-reported engaging in both cyberbullying and trolling behaviors. It is important to note that the significant correlation between cyberbullying and trolling, along with the selfreported prevalence, suggests that individuals 
are more likely to engage in both forms of electronic harassment (i.e., both cyberbullying and trolling) rather than just one. This finding has potential for future research in identifying students at risk for engaging in electronic harassment in that other forms of electronic harassment should be considered (e.g., trolling), not just cyberbullying. Finally, since previous research has yet to examine the relationship between self-esteem and internet trolling, this finding suggests that future research should continue to investigate the role of self-esteem in electronic harassment (e.g., cyberbullying and trolling).

The current study was also the first to look at the individual differences and self-esteem of individuals who engage in either one or both forms of electronic harassment. Compared to individuals who self-reported never engaging in cyberbullying or trolling behaviors, the cyberbully-only group displayed more emotional instability and antagonism. According to Eysenck (1996), individuals with high neuroticism may commit antisocial behaviors because their emotions overrule reason, and they tend to be aggressive and impulsive. For the troll-only group, the only distinguishing trait was low self-esteem; thus, trolling might be a "means to an end" for these individuals in that they are able to anonymously insult and harass individuals online in an attempt to counteract any feelings of low self-worth.

In addition, those individuals who engaged in both cyberbullying and trolling behaviors scored higher on extraversion but lower on agreeableness and self-esteem compared to the neither group. Extraversion is associated with high motivation for power, dominance, social contact, and status, but this trait can also be characterized as bold, socially adept, and assertive (Wilt \& Revelle, 2009). Thus, individuals who score high on extraversion may be motivated by the need to establish their social status, and individuals with low agreeableness (i.e., antagonism) may be more at risk for establishing their power by aggressively asserting dominance through the means of electronic harassment. In other words, these individuals may be predisposed to antisocial online behaviors (i.e., cyberbullying and trolling behaviors) because they are antagonistic and they desire social status, power, and self-worth.

Finally, the key distinguishing factors between respondents who engaged in trollingonly vs. cyberbullying-only behaviors were lower scores on neuroticism and higher scores on openness to experience. These findings are consistent with past research in that cyberbullies are more likely to be emotionally unstable and experience more depression than non-cyberbullies. Thus, neurotic individuals may respond to their negative emotions (e.g., anxiety, depression) by targeting and cyberbullying someone they know and perceive to be the source of their emotional pain. On the other hand, individuals who engage in trolling-only behaviors appear to have different objectives; they want to cause distress among random internet users for the attention and "fun of it" (Buckels et al., 2014) rather than target a specific person who is the perceived source of their anguish. In addition, the trollonly group in the current study was more open to experience (e.g., less conventional) compared to the cyberbully-only group. According to McCrae and Sutin (2009), open individuals are more humorous, expressive in their interpersonal interactions, and less likely to respond negatively to violations of norm expectations (e.g., being teased). Thus, individuals with high openness to experience may be more likely to troll because they are less sensitive to nonconventional social interactions.

Although the current study reveals new findings regarding the individual differences 
between internet trolls and cyberbullies, it is not without limitations. First, a small number of individuals in the current study self-reported engaging in troll-only behaviors $(n=20)$, which suggests that individuals are more likely to engage in both cyberbullying and trolling behaviors rather than just trolling. In addition, it is possible that the respondents could have "trolled" the survey itself. However, the authors were careful to advertise the survey as assessing "Attitudes Toward Online Communications," and the words "trolling" or "cyberbullying" never appeared in the survey. Validation questions were also present to identify individuals who were not carefully reading the questions or individuals who were randomly responding to items. The sample was also restricted to high reputation workers (i.e., 95\% and above approval ratings), meaning those individuals who have a high success rate for completing "HITS" or human intelligence tasks (see Peer, Vosgerau, \& Acquisti, 2014). Finally, there was a sex disparity in the current study in that there were more women than men; however, significant differences were still present even after running partial correlations controlling for sex. Overall, future research should continue to assess the prevalence of cyberbullying and trolling behaviors using different sampling methodologies.

\section{CONCLUSION}

A key finding in this study was the prevalence of individuals who engage in both cyberbullying and trolling behaviors. In fact, individuals were more likely to self-report both forms of electronic harassment. Thus, when addressing cyberbullying in the literature, this research suggests that it is also important to consider other forms of electronic harassment, such as trolling. In addition, the current study was the first to assess whether personality characteristics and self-esteem discriminate between self-reported cyberbullies and trolls.
The current study suggests self-esteem is an important risk factor, and future research should address how to best identify those individuals at risk for engaging in electronic harassment, and once identified, how best to mediate and treat any underlying psychosocial problems (i.e., depression). Finally, the current study identified personality characteristics differentiating individuals who engage in troll-only vs. cyberbully-only behaviors. Although cyberbullying and trolling are both forms of cyberharassment, this research suggests there are distinct differences between the types of individuals who engage in one or both of these behaviors. Future research should examine whether different personality characteristics and motivational factors (revenge, amusement) are related to different types of cyberbullying and trolling behaviors (e.g., RIP trolling vs. flaming) in this modern-day Wild Wild West. 


\section{REFERENCES}

Arıcak, O.T. (2009). Psychiatric symptomatology as a predictor of cyberbullying among university students. Egitim Arastirmalari-Eurasian Journal of Educational Research, 34, 167-184.

Berinsky, A., Huber, G., \& Lenz, G. (2011, June 20). Using Mechanical Turk as a subject recruitment tool for experimental research. Retrieved from web.mit.edu

Birnbaum, M.H. (Ed). (2000). Psychological experiments on the internet. San Diego, CA: Academic Press.

Bishop, J. (2013). The effect of deindividuation of the internet troller on criminal procedure implementation: An interview with a Hater. International Journal of Cyber Criminology, 7(1), 28-48.

Brack, K., \& Caltabiano, N. (2014). Cyberbullying and self-esteem in Australian adults. Cyberpsychology: Journal of Psychosocial Research on Cyberspace, $8(2)$.

Bryce, J., \& Fraser, J. (2013). "It's common sense that it's wrong": Young people's perceptions and experiences of cyberbullying. Cyberpsychology, Behavior, and Social Networking, 16(11), 783-787.

Buckels, E.E., Trapnell, P.D., \& Paulhus, D.L. (2014). Trolls just want to have fun. Personality and Individual Differences, 67, 97-102.

Buhrmester, M., Kwang, T., \& Gosling, S.D. (2011). Amazon's Mechanical Turk: A new source of inexpensive, yet high-quality data? Perspectives on Psychological Science, 6(1), 3-5.

Casas, J., Del Ray, R., \& Ortega-Ruiz, R. (2013). Bullying and cyberbullying:
Convergent and divergent predictor variables. Computers in Human Behavior, 29(3), 580-587.

Celik, S., Atak, H., \& Erguzen, A. (2012). The effect of personality on cyberbullying among university students in Turkey. Eurasian Journal of Educational Research, (49), 129-150.

Corcoran, L., Connolly, I., \& O'Moore, M. (2012). Cyberbullying in Irish schools: An investigation of personality and selfconcept. The Irish Journal of Psychology, 33(4), 153-165.

Corcoran, L., McGuckin, C., \& Prentice, G. (2015). Cyberbullying or cyber aggression?: A review of existing definitions of cyberbased peer-to-peer aggression. Societies, 5, 245-255.

Costa, P.T., \& McCrae, R.R. (1992). Revised NEO personality inventory (NEO-PI-R) and NEO five-factor inventor (NEO-FFI) professional manual. Odessa, FL: Psychological Assessment Resources, Inc.

Del Rey, R., Elipe, P. \& Ortega-Ruiz, R. (2012). Bullying and cyberbullying: Overlapping and predictive value of cooccurrence. Psicothema, 24(4), 608-613.

Diamanduros, T., Downs, E., \& Jenkins, S.J. (2008). The role of school psychologists in the assessment, prevention, and intervention of cyberbullying. Psychology in the Schools, 45(8), 693-704.

Egan, V. (2009). The 'Big Five': Neuroticism, extraversion, openness, agreeableness and conscientiousness as am organizational scheme for thinking about aggression and violence. In M. McMurran \& R.C. Howard (Eds.). Personality Disorder and Violence: 
An Evidence Based Approach (pp. 63-84) United Kingdom: John Wiley \& Sons, Ltd.

Erdur-Baker, Ö. (2010). Cyberbullying and its correlation to traditional bullying, gender and frequent and risky usage of internetmediated communication tool. New Media Society, 12(1), 109-125.

Eysenck, H.J. (1996). Personality and crime: Where do we stand. Psychology, Crime, and Law, 2(3), 143-152.

Festl, R., \& Quandt, T. (2013). Social relations and cyberbullying: The influence of individual and structural attributes on victimization and perpetration via the internet. Human Communication Research, 39(1), 101-126.

Frisén, A., Jonsson, A., Persson, C. (2007). Adolescents' perception of bullying: Who is the victim? Who is the bully? What can be done to stop bullying? Adolescence, 42(168), 749-761.

Gámez-Guadix, M., Orue, I., Smith, P., \& Calvete, E. (2013). Longitudinal and reciprocal relations of cyberbullying with depression, substance abuse use, and problematic internet use among adolescents. Journal of Adolescent Health, 53(4), 446-452.

Gibb, Z.G., \& Devereux, P.G. (2014). Who does that anyway? Predictors and personality correlates of cyberbullying in college. Computers in Human Behavior, 38, $8-16$.

Grigg, D.W. (2010). Cyber-aggression: definition and concept of cyberbullying. Australian Journal of Guidance and Counselling, 20(2), 143-156.

Hardaker, C. (2010). Trolling in asynchronous computer-mediated communication: From user discussions to academic definitions.
Journal of Politeness Research, 6(2), 215242.

Hinduja, S., \& Patchin, J. (2010). Bullying, Cyberbullying, and Suicide. Archives of Suicide Research, 14(3), 206-221.

Jankauskiene, R., Kardelis, K., Sukys, S., Kardeliene, L. (2008). Associations between school bullying and psychosocial factors. Social Behavior and Personality, 36(2), 145-162.

Kokkinos, C.M., Antoniadou, N., Markos, A. (2014). Cyber-bullying: An investigation of the psychological profile of university student participants. Journal of Applied Developmental Psychology, 35(3), 204-214.

Krueger, R.F., \& Tackett, J.L. (Eds.). (2006). Personality and Psychopathology. New York, NY: The Guilford Press.

MacDonald, C.D., Roberts-Pittman, B. (2010). Cyberbullying among college students: Prevalence and demographic differences. Procedia Social and Behavioral Sciences, 9, 2003-2009.

McCrae, R.R., \& Sutin, A.R. (2009). Openness to experience. In M.R. Leary and R.H. Hoyle (Eds.). Handbook of Individual Differences in Social Behavior (pp. 257273). New York, NY: The Guilford Press.

Menesini, E., Nocentini, A., Palladino, B.M., Frisén, A., Berne, S., Ortega-Ruiz, R., Calmaestra, J., Scheihauer, H., . . . Smith, P.K. (2012). Cyberbullying definition among adolescents: A comparison across six European countries. Cyberpsychology, Behavior, and Social Networking, 15(9), 455-463.

Miller, J.D., Lynam, D.R., \& Jones, S. (2008). Externalizing behavior through the lens of the five-factor model: A focus on agreeableness and conscientiousness. 
Journal of Personality Assessment, 90(2), 158-164.

Ojedokun, O., \& Idemudia, E.S. (2013). The moderating role of emotional intelligence between PEN personality factors and cyberbullying in a student population. Life Science Journal. 10(3). 1924-1930.

O'Moore, M. \& Kirkham (2001). Self-esteem and its relationship to bullying behavior. Aggressive Behavior, 27(4), 269-283.

Ozden, M.S., \& Icellioglu, S. (2013). The perception of cyberbullying and cybervictimization by university students in terms of their personality factors. Procedia: Social and Behavioral Sciences, 116, 4379-4383.

Patchin, J.W., \& Hinduja, S. (2006). Bullies move beyond the schoolyard: A preliminary look at cyberbullying. Youth Violence and Juvenile Justice, 4(2), 148-169.

Patchin, J.W., \& Hinduja, S. (2010). Cyberbullying and self-esteem. Journal of School Health, 80(12), 614-621.

Peer, E., Vosgerau, J., \& Acquisti, A. (2014). Reputation as a sufficient condition for data quality on Amazon Mechanical Turk. Behavior Research Methods, 46(4), 10231031.

Phillips, W. (2011). LOLing at tragedy: Facebook trolls, memorial pages and resistance to grief online. First Monday, 16(12).

Phillips, W. (2015). This is why we can't have nice things: Mapping the relationship between online trolling and mainstream culture. Cambridge, MA: Massachusetts Institute of Technology.

Renati, R., Berrone, C., \& Zanetti, M. (2012). Morally disengaged and unempathic: Do cyberbulllies fit these definitions? An exploratory study. Cyberpsychology,
Behavior, and Social Networking, 15(8), 391-398.

Rigby, K., \& Slee, P. (1991). Bullying among Australian school children: Reported behavior and attitudes toward victims. The Journal of Social Psychology, 131(5), 615627.

Rogers, M. (2001). A social learning theory and moral disengagement analysis of criminal computer behavior: An exploratory study. Unpublished dissertation, University of Manitoba, Canada.

Rogers, M., Seigfried, K., \& Tidke, K. (2006a). Self-reported computer criminal behavior: A psychological analysis. Digital Investigation, 3, 116-120.

Rogers, M., Smoak, N.D., \& Liu, J. (2006b). Self-reported computer criminal behavior: A big-5, moral choice and manipulative exploitive behavior analysis. Deviant Behavior, 27, 1-24.

Rosenberg, M. (1965). Society and the adolescent self-image. Princeton, NJ: Princeton University Press.

Salmivalli,C., Kaukiainen, A., Kaistaniemi, L., \& Lagerspez, K.M.J. (1999). Self-evaluated self-esteem, peer-evaluated self-esteem, and defensive egotism as predictors of adolescents' participation in bullying situations. Personality and Social Psychology Bulletin, 25(10), 1268-1278.

Santana, A.D. (2014). Virtuous or Vitriolic: The effect of anonymity on civility in online newspaper reader comment boards. Journalism Practice, 8(1), 18-33.

Schachaf, P., \&, Hara, N. (2010). Beyond vandalism: Wikipedia trolls. Journal of Information Science, 36(3), 357-370.

Schenk, A.M., Fremouw, W.J., \& Keelan, C.M. (2013). Characteristics of college 
cyberbullies. Computers in Human Behavior, 29(6), 2320-2327.

Schenk, A.M., \& Fremouw W.J. (2012). Prevalence, psychological impact, and coping of cyberbully victims among college students. Journal of School Violence, 11(1), 21-37.

Seigfried-Spellar, K.C., \& Treadway, K.N. (2014). Differentiating hackers, identity thieves, cyberbullies, and virus writers by college major and individual differences. Deviant Behavior, 35(10), 782-803.

Smith, P.K., Mahdavi, J., Carvalho, M., Fisher, S., Russell, S., \& Tippett, N. (2008). Cyberbullying: Its nature and impact in secondary school pupils. Child Psychology and Psychiatry, 49(4), 376-385.

Stanglin, D., \& Welch, W. (2013, October 16). Two girls arrested on bullying charges after suicide. USA Today. Retrieved from http://www.usatoday.com

Sticca, F., Ruggieri, S., Alsaker, F., \& Perren, S. (2013). Longitudinal risk factors for cyberbullying in adolescence. Journal of Community \& Applied Social Psychology, 23(1), 52-67.

Stopcyberbullying.org, n.d. "Are you a cyberbully?" Retrieved on May 10, 2014 from

http://stopcyberbullying.org/kids/are_you _a_cyberbully.html.

Suler, J. (2004). The online disinhibition effect. Cyberpsychology \& Behavior, 7(3), 321-326.

Tabachnick, B., \& Fidell, L. (2007). Using Multivariate Statistics (5 $5^{\text {th }}$ ed.). Boston, MA: Pearson Education.

Thompson, N. (2013, July 15). Internet trolls: What to do about the scourge of the web? CNN World. Retrieved from http://www.cnn.com
Tokunaga, R.S. (2010). Following you home from school: A critical review and synthesis of research on cyberbullying victimization. Computers in Human Behavior, 26, 277287.

Vandebosch, H. \& Van Cleemput, K. (2009). Cyberbullying among youngsters: Profiles of bullies and victims. New Media and Society, 11(8), 1349-1371.

Warner, R.M. (2007). Applied statistics: From bivariate through multivariate techniques. Thousand Oaks, CA: Sage Publications, Inc.

Whiteside, S.P., \& Lynam, D.R. (2001). The five-factor model and impulsivity: Using a structural model of personality to understand impulsivity. Personality and Individual Differences, 30, 699-689.

Widiger, T. (2004). Five factor model rating form (FFMRF). Retrieved from www.uky.edu/ ${ }^{\sim}$ widiger /ffmrf.rtf

Wilt, J., \& Revelle, W. (2009). Extraversion. In M.R. Leary, \& R.H. Hoyle (Eds.), Handbook of Individual Differences in Social Behavior (pp. 27-45). New York, NY: The Guilford Press. 
